\title{
Cenizas de calderas dendroenergéticas. III Efecto amortiguador sobre la fijación de fósforo en suelos ácidos con aluminio activo*
}

\author{
Wood ashes III: Buffer effects on phosphorus fixation in acid soils with active aluminium \\ C.D.O.: $232.322 .41-114.262$
}

RENATO GREZ, VICTOR GERDING

Universidad Austral de Chile, Facultad de Ciencias Forestales, Instituto de Silvicultura, Casilla 567, Valdivia, Chile.

SUMMARY

The effects of wood ash on the dynamics of phosphorus in aluminium-laden soils of south-central Chile were determined. Additions of $0,100,200$, and $400 \mathrm{~kg} / \mathrm{ha}$ of triple-superphosphate along with additions of $0,5,10$, and $20 \mathrm{t} / \mathrm{ha}$ of ash were used in the study to determine to what extent ash lessens phosphorus fixation. Additions of ash effectively lessened phosphorus fixation, and by recycling it in this way, ash could be eliminated from the category of residual waste.

\section{RESUMEN}

Se determinó el efecto de cenizas de calderas dendroenergéticas sobre la dinámica del fósforo en suelos de la zona centro sur de Chile que poseen aluminio activo. Dosis de 0, 100, 200 y $400 \mathrm{~kg} / \mathrm{ha}$ de superfosfato triple y de 0,5 , 10 y 20 t/ha de ceniza utilizadas en el ensayo permitieron constatar el efecto positivo de la ceniza al disminuir la fijación de fósforo, corroborando la posibilidad de su utilización y por lo tanto de su reciclaje, eliminándola de su categoría de residuo.

\section{INTRODUCCION}

La fijación de fósforo constituye uno de los principales problemas en suelos con altos niveles de aluminio activo. La eliminación o atenuación de este problema pasa necesariamente por contrarrestar su reactividad, siendo una alternativa la aplicación de enmiendas alcalinas que conducen a la precipitación de hidróxido de aluminio de baja solubilidad (Haynes, 1984). Dado el carácter alcalino y composición química de las cenizas de calderas dendroenergéticas se ha considerado de interés estudiar su efecto sobre la disponibilidad de fósforo, aparte de su contribución sobre el nivel de elementos nutritivos, como ha sido demostrado anteriormente (Grez et al., 1992a y b).

Proyecto Fondecyt 89-0199.

\section{MATERIAL Y METODOS}

Suelos. Se recolectaron tres suelos de la zona centro sur de Chile: trumao, rojo arcilloso y pardo metamórfico, los que han sido descritos previamente (Grez et al., 1992a y b).

Ceniza y fertilizante. La ceniza fue recolectada de caldera abastecida con restos de madera de Pinus radiata D. Don y tamizada bajo $2 \mathrm{~mm}$. Su composición química fue determinada en un trabajo anterior (Grez et al., 1992a). El fertilizante corresponde a un superfosfato triple de origen comercial, con $46 \%$ de $\mathrm{P}_{2} \mathrm{O}_{5}$.

Ensayo de incubación. Para estudiar el efecto de la ceniza sobre la disponibilidad de fósforo se prepararon por duplicado mezclas de cada suelo con combinaciones de ceniza y de superfosfato triple. Las dosis equivalentes utilizadas correspondieron a $0,100,200 \mathrm{y} 400 \mathrm{~kg} / \mathrm{ha}$ de superfosfato y 
de $0,5,10$ y $20 \mathrm{t} / \mathrm{ha}$ de ceniza, para $10 \mathrm{~cm} \mathrm{de}$ profundidad.

Al cabo de 12 semanas de incubación, en que semanalmente se regó para mantener el suelo húmedo, se recolectaron muestras para análisis químico. Fósforo disponible fue determinado por el método de Olsen (Olsen y Sommers, 1982) y aluminio activo por extracción con acetato de amonio a pH 4.8 (Mc Lean et al., 1959).

El diseño correspondió a un factorial de fósforo y ceniza para cada suelo. Los resultados de fósforo y aluminio fueron sometidos a análisis de varianza $(\mathrm{P}<0.05)$.

\section{RESULTADOS Y DISCUSION}

El efecto de aplicaciones de ceniza sobre la dinámica de fósforo en diferentes suelos, en parti- cular aquellos que presentan una elevada actividad de aluminio y por lo tanto de capacidad de fijación de fosfatos, se presenta en el cuadro 1.

Como se aprecia, luego de 12 semanas de incubación, para cada dosis de superfosfato triple existe en general un incremento en la disponibilidad de fósforo con las dosis de ceniza. Esto es más evidente en el suelo trumao que posee mayores contenidos de aluminio y menos para los suelos rojo arcilloso y metamórfico. Simultáneamente, con el aumento de dosis de ceniza ocurre en los tres suelos una disminución del aluminio extractable en acetato de amonio a pH 4.8 o "aluminio activo", al cual se atribuye una importante participación en la fijación de fósforo (Prasad y Motto, 1982). Es decir, se logra mitigar el efecto antagónico del aluminio en forma similar a lo obtenido por Curtin y Smillie (1984) mediante encalado, concluyéndose que las cenizas de calde-

\section{CUADRO 1}

Niveles (mg/kg) de P Olsen y de Al extractable (en acetato de amonio pH 4.8) en diferentes suelos y para distintas dosis de ceniza y de superfosfato triple.

Levels (in $\mathrm{mg} / \mathrm{kg}$ ) of phosphorus (Olsen) and extractable aluminium (in amonium acetate at $\mathrm{pH} 4.8$ ) in various soils and for distinct additions of ash and triple-superphosphate.

\begin{tabular}{|c|c|c|c|c|c|c|c|}
\hline \multirow{2}{*}{$\begin{array}{l}\text { Dosis } \\
\text { ceniza } \\
\mathrm{kg} / \mathrm{ha}\end{array}$} & \multirow{2}{*}{$\begin{array}{c}\text { Dosis } \\
\text { SFT } \\
\mathrm{kg} / \mathrm{ha}\end{array}$} & \multicolumn{2}{|c|}{$\begin{array}{l}\text { Suelo rojo } \\
\text { arcilloso }\end{array}$} & \multicolumn{2}{|c|}{$\begin{array}{c}\text { Suelo } \\
\text { metamórfico }\end{array}$} & \multicolumn{2}{|c|}{$\begin{array}{l}\text { Suelo } \\
\text { trumao }\end{array}$} \\
\hline & & $\mathrm{P}$ & $\mathrm{Al}$ & $\mathrm{P}$ & $\mathrm{Al}$ & $\mathrm{P}$ & $\mathrm{Al}$ \\
\hline \multirow{4}{*}{0} & 0 & 7 & 185 & 2 & 475 & 3 & 1661 \\
\hline & 100 & 11 & 185 & 9 & 483 & 10 & 1987 \\
\hline & 200 & 21 & 172 & 20 & 444 & 16 & 1638 \\
\hline & 400 & 44 & 160 & 39 & 443 & 27 & 1613 \\
\hline \multirow{4}{*}{5} & 0 & 10 & 147 & 6 & 404 & 6 & 1548 \\
\hline & 100 & 16 & 138 & 12 & 393 & 12 & 1439 \\
\hline & 200 & 19 & 138 & 19 & 374 & 21 & 1465 \\
\hline & 400 & 34 & 137 & 40 & 349 & 37 & 1375 \\
\hline \multirow{5}{*}{10} & 0 & 12 & 112 & 5 & 367 & 10 & 1381 \\
\hline & 100 & 17 & 114 & 11 & 332 & $21 "$ & 1335 \\
\hline & 200 & 24 & 104 & 19 & 314 & 26 & 1291 \\
\hline & 400 & 41 & 115 & 41 & 291 & 35 & 1297 \\
\hline & 0 & 19 & 109 & 11 & 272 & 16 & 1297 \\
\hline \multirow{3}{*}{20} & 100 & 22 & 104 & 16 & 251 & 23 & 1319 \\
\hline & 200 & 29 & 93 & 20 & 234 & 30 & 1326 \\
\hline & 400 & 41 & 93 & 41 & 213 & 45 & 1268 \\
\hline
\end{tabular}


ras dendroenergéticas representan un residuo de gran valor para ser aplicado a los suelos con este tipo de problemas.

Si a este efecto se le suma el aporte en elementos nutritivos como potasio y calcio, entre otros, demostrado en un trabajo anterior (Grez et al., 1992b), se corrobora la potencialidad de eliminación de este residuo industrial por reciclaje.

\section{CONCLUSIONES}

La ceniza produjo un aumento significativo de la disponibilidad de fósforo en todos los suelos. En combinación con superfosfato triple la ceniza incrementó significativamente la fracción disponible de fósforo que aporta el fertilizante en todas sus dosis para el suelo trumao, en sus dosis media y baja para el suelo rojo arcilloso y sólo en su dosis baja para el suelo metamórfico. La ceniza redujo significativamente la concentración de aluminio activo en todos los suelos y este efecto fue mayor con el incremento de las dosis de superfosfato triple.

\section{BIBLIOGR AFIA}

CURTIN, D., G.W. SMILLIE. 1984. Influence of liming on soluble and labile $\mathrm{P}$ in fertilized soil. Commun. in soil Sci. Plant Anal. 15(2): 177-184.

GREZ, R., V. GERDING, F. UNION. 1992a. "Cenizas de calderas dendroenergéticas. I Acción como enmienda alcalina en suelos de la zona sur de Chile", Bosque 13(2): 33-38.

GREZ, R., V. GERDING, F. UNION. 1992b. "Cenizas de calderas dendroenergéticas. II Residuo industrial utilizable como mejorador de la fertilidad de suelos", Bosque 13(2): 39-44.

HAYNES, R.J. 1984. "Lime and phosphate in the soil-plant system", Advances in Agronomy 37: 249-315.

Mc LEAN, E.O., M.R. HEDDLESON, G.J. POST. 1959. "Aluminium in soils: III. A comparison of extraction methods in soils and clays", Soil Sci. Soc. Am. Proc. 23: 289-293.

OLSEN, S.R., LE. SOMMERS. 1982. Methods of soil analysis. Part 2. Chemical and Microbiological Properties. Agronomy Monograph $\mathrm{N}^{\circ} 9$ (2nd ed.). ASA-SSSA: 403-429.

PRASAD, S.S., H.L. MOTTO. 1982. "Retention of applied P by volcanic ash soils - influence on available $\mathrm{P}$ and soluble Al", Commun. in Soil Sci. Plant Anal. 13(6): 441-452. 